synonym is added in italics. A comprehensive index completes the monograph.

\section{Eye Examinations of Asian School Children}

THE eyes of 359 children attending the Indian public primary school in Mwanza have been examined by members of the Biochemistry Nutrition Division of the East African Institute for Medical Research (Report, 1959-60. Pp. ii +36. Mwanza: East African Institute for Medical Research, 1960. Sh. 3). Apart from refractive errors there was almost no eye disease. Heights and weights were also obtained and all the data have been prepared so that comparison can be made with a similar study made by Pendse (1954) in Poona. This is the first time that refractive errors and growth data have been compared for two closely related communities in different parts of the world. In both height and weight the Gujerat children of Mwanza are superior to the Maratas of Poona. It is postulated that the greater growth of the Mwanza children is due to the improved conditions under which they now live in East Africa. The Mwanza refraction data showed a marked excess of emmetropic and near-emmetropic refractions compared with the normal distribution and also a myopic excess and a prolongation of the myopic tail. When a comparison is made of the percentage distribution of refraction in the Mwanza and the Poona children, close similarity is seen. Mixed astigmatism and anisometropia were present in $6 \cdot 6$ per cent and $8 \cdot 6$ per cent respectively of these children. These figures occupy a position intermediate between those of the Mwanza African children and those for Mvuni African children. About 1 per cent of the children had squint and less than 1 per cent were wearing glasses at the time of the examination. These Asian children were also examined for the presence and degree of water cleft opacities in the periphery of the lens. Comparison of the details shows that the incidence was slightly lower than in the Mwanza African children.

\section{Journal of the Association for Computing Machinery}

The January 1961 issue of the Journal of the Association for Computing Machinery contains six major papers, at least three of which will be of general interest. The first of these, by Herbert Keller, is an analysis of finite automata with special reference to pattern recognition. The main theme is a description of various 'perceptrons', a mysterious term which for some time has puzzled British users of computers, being claimed by some to hide a concept of deep significance, and by others to be a triviality. Keller takes as his definition something which is usually regarded in Britain as a variety of synthetic neurone, and his analysis of the potentialities of this class of device will, no doubt, stimulate discussion. Ivan Flores contributes a paper which analyses the use of computers as sorting machines. This particular class of operation is one which does not show the machines at their best so that analyses which estimate efficiencies are always useful. Probably the most generally interesting contribution is that by Leiner and Youden on generating pronounceable names on a computer. Their particular names have four letters and an amusing touch is their lament: " . . some of the computer-generated words, although highly efficient phonetically, were semantically unsuited for permanent inclusion in the records". It seems that some humans had to draw up a proscribed list before the records were fit for publication.

\section{The Pontide Paradox}

ACCORDING to a number of prominent geologists, the region occupied by the present Black Sea ('Pontus Euxinus' of the ancients), even as late as the second half of the Tertiary era, was occupied by a land mass called Pontide. Furthermore, according to this hypothesis the present Crimean mountains represent the northern fringe of this land mass untouched by a widespread subsidence affecting the greater part of this continent. On the other hand, some geologists query the idea of the existence of Pontide in the late Tertiary era, and their views are supported by M. V. Muratov (Priroda, 6, 57; 1960), who, in a series of palæogeographical maps, illustrates the evolution of the future Black Sea from its initial stages to the northern geosyncline of the Tethys. Such a hypothesis also finds its support in the observed peculiarities of the present-day flora and fauna of the Crimea. These biogeographical data, on the other hand, provide N. I. Rubtzov (Priroda, 8, 83; 1960) with an additional argument in the support of the hypothesis of the existence of Pontide.

\section{Cultural Sequences in Hokkaido, Japan}

QUITE a lot is known about the prehistory of China. Pekin man and the stone-age industry found in the cave with his remains have at least given a start for the study of the earliest cultures of that vast region. Again, not a few of the museums in Britain display painted pots of Neolithic datethe earliest of a long line of painted pottery from China. Much less is known about the earliest history of Japan. The article by Lieut.-Col. H. A. MacCord in a recent paper (Proc. U.S. Nat. Mus. (No. 3443, Vol. 112) : Pp. 481-503 + 14 plates. Washington, D.C. : Government Printing Office, 1960) does not profess to fill this gap, but does describe some research work undertaken during 1953-54 in the island of Hokkaido, in the region of the Ishikari Plain. Pottery, most of it decorated, and stone tools were found, and many of these are illustrated in 14 full pages of half-tones. The stone tools include polished 'celts', knives and arrow heads, some of obsidian. Some day we shall hope to see a volume on Japanese prehistory; the results published here will certainly merit inclusion in all libraries of archæology and ethnology.

\section{The Advisory Group for Aeronautical Research and Development}

THE Advisory Group for Aeronautical Research and Development announces the following schedule of meetings : June 5-9, Documentation Committee on "Exchange of Information in the Nato Countries" (Paris); July 12-19, Seminar on Astronautics, jointly sponsored by the University of Southampton and AGARD (Southampton); July 18-21, Fluid Dynamics Panel on "The Use of Rocket Vehicles in Flight Research" (The Hague) ; July 24-26, Avionics Panel Technical Meeting on "Microminiaturization" (Oslo); Structures and Materials Panel Specialists' Meeting of the Material Group (Oslo) ; July 27-28, 11th AGARD General Assembly, "Scientific Goals of Space Exploration and Research" (Oslo) ; July 31August 2, Avionics Panel Technical Meeting on "Low-noise Electronics" (Oslo).

\section{Field Studies Council: Summer and Autumn Courses}

THE Field Studies Council has announced the programmes of special courses to be held during 